\title{
Clínica da Atividade Docente e intervenções a partir da autoconfrontação e da instrução ao sósia
}

\author{
Siderlene Muniz-Oliveira ${ }^{1}$ \\ Anselmo Lima² \\ Dalvane Althaus ${ }^{3}$
}

\section{Resumo}

O objetivo deste artigo é apresentar uma proposta de implementação de uma Clínica da Atividade Docente, seguida de uma explanação de dois métodos que podem ser utilizados nesse processo, a autoconfrontação e a instrução ao sósia. Para exemplificar a sua utilização, serão apresentados dois tipos de ação de intervenção com esses métodos. O primeiro foi realizado com professores universitários de diferentes áreas com o método autoconfrontação; o segundo, com professores do ensino fundamental e médio da rede estadual de ensino com o método instrução ao sósia, tendo como observadores alunos de licenciatura, futuros professores. Os resultados mostram a importância desses métodos, tanto para formação inicial quanto para formação continuada, tendo os professores como protagonistas de seu trabalho.

Palavras-chave: Clínica da Atividade; Docência; Autoconfrontação; Instrução ao Sósia.

\section{Teaching Activity Clinic and interventions based on self-confrontation and instruction to the double}

\begin{abstract}
This paper aims to present a proposal for an implementation of a Teaching Activity Clinic, followed by an explanation of two methods that can be used in this process, self-confrontation and instruction to the double. To exemplify its use, two types of intervention action using these methods will be presented. The first was carried out with university professors from different areas using the self-confrontation method; the second, with elementary and high school teachers from the state school system using the instruction to the double method, with undergraduate students, future teachers, as observers. The results show the importance of these methods, both for initial and continuing education, with teachers as protagonists of their work.

Keywords: Activity Clinic; Teaching; Self-Confrontation; Instruction to the Double.
\end{abstract}

\section{Introdução}

A Clínica da Atividade, vertente da Psicologia do Trabalho, originou-se no Conservatório Nacional de Artes e Ofícios (CNAM) em Paris, tendo como preocupação a saúde e desenvolvimento do trabalhador (CLOT, 2006, 2010). Ela vem, cada vez mais, gerando grande

\footnotetext{
${ }^{1}$ Universidade Tecnológica Federal do Paraná, Pato Branco, smoliveira@utfpr.edu.br

${ }^{2}$ Universidade Tecnológica Federal do Paraná, Pato Branco, anselmo@utfpr.edu.br

${ }^{3}$ Universidade Tecnológica Federal do Paraná, Pato Brando, dalvane@utfpr.edu.br
} 
influência em outros países, como no Brasil. Esse fato pode ser observado nos artigos científicos publicados no número temático do Periódico Horizontes do Programa de Pósgraduação em Educação da Universidade São Francisco, Itatiba, SP, em 2017, denominado A clínica da atividade e suas repercussões no contexto brasileiro ${ }^{4}$. Nesse número temático, podem-se observar, majoritariamente, pesquisas e intervenções realizadas no âmbito educacional.

O objetivo deste artigo é ampliar o debate científico em relação a pesquisas e intervenções na área educacional utilizando, como fundamentação, a Clínica da Atividade e seus métodos, autoconfrontação e instrução ao sósia. Desse modo, na próxima seção, será apresentada, primeiramente, uma proposta para a implementação de uma Clínica de Atividade Docente para professores que atuam em diversos níveis educacionais (LIMA, 2021); em segundo lugar, explana-se sobre o dispositivo metodológico de autoconfrontação, com a apresentação de um relato de uma intervenção com este método em uma universidade; em terceiro lugar, será feito um relato de uma intervenção com o método instrução ao sósia, realizado em uma universidade, com a colaboração de professores da educação básica, ensino fundamental e ensino médio.

\section{Clínica da Atividade Docente: proposta para uma implementação}

A docência tem sido maltratada há muito tempo (CLOT, 2016) e os impactos negativos dos maus tratos recaem quase totalmente sobre os trabalhadores que exercem a profissão. Salas superlotadas, mal iluminadas, com temperaturas fora do controle, além de uma série de dificuldades decorrentes, por exemplo, da indisciplina dos alunos, atentam todos os dias contra o trabalho e a saúde dos professores.

Esse quadro se agrava ao se considerar que muitos educadores dobram e, às vezes, triplicam sua carga semanal de aulas num esforço de obter uma remuneração um pouco mais digna ao final do mês. Não surpreende que, nessas condições, seja alarmante o número de professores que adoecem, faltam ou afastam-se do trabalho a cada semana e que, nas mesmas

\footnotetext{
${ }^{4}$ Disponível em: https://revistahorizontes.usf.edu.br/horizontes/issue/view/24. Acesso em: 13 out. 2020.
} 
condições, a qualidade da educação em nosso país seja uma das piores do mundo! (BERMÚDEZ, 2019).

O caminho para reverter esse quadro não é tratar a saúde dos professores depois que eles adoecem, nem lhes oferecer mais "treinamentos", que, em sua forma tradicional, deliberadamente fecham os olhos e viram as costas para a realidade concreta da sala de aula.

O caminho é cuidar da profissão docente em parceria com os professores e enfrentar junto com eles os obstáculos e dificuldades reais da sala de aula.

Se os docentes estão ou ficam doentes, isso se deve com muita frequência ao fato de que, como resultado dos maus tratos sofridos, sua profissão está e fica doente antes deles! Isso se deve também, muitas vezes, à precariedade e à insalubridade da própria sala de aula.

Para que os professores se desenvolvam como profissionais e para que não adoeçam no exercício da profissão, uma proposta prática é que a formação continuada e a saúde do professor sejam promovidas nas escolas por meio de uma Clínica da Atividade Docente.

Seguindo uma sólida perspectiva inaugurada e desenvolvida ao longo de mais de vinte anos pelo Psicólogo do Trabalho Yves Clot, "clínica" não corresponde aqui de forma alguma à ideia de um "lugar aonde vão os doentes consultar um médico, receber tratamento ou submeter-se a exames", tal como apresentada pelo dicionário Aurélio (FERREIRA, 2000).

Trata-se, em vez disso, de fazer das escolas e das salas de aula o lugar preciso em que os próprios professores buscam, em parceria com os formadores e demais gestores educacionais, desenvolver práticas de ensino-aprendizagem ao mesmo tempo em que identificam e trabalham para superar a precariedade, que - com muita frequência - se traduz em diversos obstáculos e dificuldades insuperáveis se os professores não forem incentivados e apoiados pela gestão. O desenvolvimento profissional assim garantido funciona como um fundamental operador de saúde no próprio trabalho para os docentes. Essa perspectiva clínica, como ação prática de promoção simultânea tanto da formação continuada quanto da saúde do professor nas escolas, tem a grande vantagem de não esperar que o professor adoeça para depois, talvez, cuidar de sua saúde sem nada alterar em suas condições de trabalho.

A proposta aqui é cuidar da profissão docente junto com os professores para que eles ao exercê-la - se desenvolvam e se realizem como profissionais. A promoção da saúde no trabalho é o resultado dessa realização. 
A implementação de uma Clínica da Atividade Docente nas escolas como forma de nelas promover a formação continuada e a saúde dos professores deve partir da demanda dos próprios professores e não trapacear com a realidade da educação.

A questão aqui não é somente a demanda de aumento salarial, que existe, é legítima e inquestionável: os professores devem ser muito melhor remunerados do que são hoje e é obrigação dos gestores, em articulação com os governos federal, estadual e municipal, buscar os meios de corresponder plenamente a esse anseio.

Trata-se também, e principalmente, de uma demanda de pelo menos três ordens:

1) os professores querem e precisam ser reconhecidos e respeitados como especialistas na atividade que desenvolvem;

2) os professores querem e precisam ter melhores condições de trabalho, especialmente em sala de aula; e

3) os professores querem e precisam de um programa de formação continuada que os respeite como especialistas naquilo que fazem e que se preocupe com sua saúde, não fechando os olhos e não virando as costas para a precariedade de suas condições de trabalho.

Quando certos resultados educacionais esperados pelo governo e pela sociedade não são alcançados (o que acontece com muita frequência!), é muito comum que os docentes sejam responsabilizados e considerados incompetentes: - "não sabem fazer isso", "não sabem fazer aquilo", "não estão preparados para isso", "não estão preparados para aquilo" etc.

Raramente, considera-se que, com poucas exceções, são as condições precárias das escolas que levam os professores a não conseguirem realizar a contento o trabalho que lhes é confiado. O fato é que a eliminação da precariedade das escolas exige altos investimentos da parte do governo. É também que "sai muito mais barato" alegar que os professores são despreparados e que aquilo que lhes falta é, "na verdade", mais "treinamentos", ou mais "oficinas", ou mais "cursos", ou mais "palestras", ou mais "workshops", ou - em suma - mais "competência".

Não é de se admirar que em torno desses fatos tenha surgido e se organizado a indústria dos especialistas externos na atividade docente, que pouco ou nada conhecem da realidade cotidiana das escolas ou que, ao contrário, a conhecem muito bem, mas jogam o jogo de acordo com obscuras regras estabelecidas... 
Partir da demanda real dos professores e não trapacear com a realidade da educação é o primeiro passo para a implementação de uma Clínica da Atividade Docente nas escolas. Essa é a demanda. Não se deve trapacear com a realidade.

O segundo passo na implementação de uma Clínica da Atividade Docente nas escolas é a constituição de um coletivo de professores a partir de determinadas estruturas educacionais.

Não se deve confundir coletivo de professores com coleções de indivíduos. O que espontânea e normalmente existe nas escolas são as coleções de indivíduos. É a partir delas que se deve constituir o coletivo de professores.

Isso se faz, em um primeiro momento, apresentando-se detalhadamente a proposta de trabalho aos docentes e obtendo-se sua adesão para participar. Se a apresentação for séria e bem-feita, eles compreenderão e apoiarão a iniciativa. O dimensionamento do coletivo de professores a ser constituído dependerá tanto do alcance pretendido para a ação quanto do apoio e comprometimento formal dos gestores responsáveis pela estrutura educacional em que se vai atuar.

Apresentamos, a seguir, três possibilidades de dimensionamento que consideramos fundamentais do ponto de vista operacional para escolas da educação básica. Uma se articula à outra de modo progressivo: 1) Localmente, com o apoio e comprometimento formal do Diretor, os Coordenadores Pedagógicos de uma escola podem juntos trabalhar na constituição de um coletivo de professores no âmbito de um período, de alguns períodos ou de todos os períodos de trabalho da escola: manhã e/ou tarde e/ou noite. O número de professores participantes aumenta ou diminui conforme a quantidade de períodos.

2) Na esfera de uma região, com o apoio e comprometimento formal da Chefia do Núcleo Regional de Educação (ou da Diretoria de Ensino), uma equipe de pedagogos pode constituir um coletivo de professores mais amplo, no âmbito de um conjunto de escolas ou, o que seria melhor, de todas as escolas vinculadas ao Núcleo ou à Diretoria. Nesse caso, a equipe de pedagogos precisará contar com os Diretores e Coordenadores Pedagógicos dessas escolas.

3) No Estado, com o apoio e comprometimento formal do Secretário Estadual de Educação, uma Equipe de Formadores pode constituir um coletivo de professores ainda mais amplo, no âmbito de todas as escolas vinculadas à Secretaria. Nesse caso, a equipe de formadores precisará contar com as chefias e equipes de pedagogos dos Núcleos de Educação 
(ou das Diretorias de Ensino) e estas precisarão contar com os Diretores e Coordenadores Pedagógicos das escolas. No caso de uma Secretaria Municipal de Educação, o coletivo de professores pode ser constituído no âmbito de todas as escolas do Município.

É importante ressaltar que, como sugerido, o dimensionamento deste último coletivo de professores (3) pressupõe, em seu interior, o dimensionamento do anterior (2) e que este, por sua vez, pressupõe, também em seu interior, o dimensionamento do primeiro (1). Trata-se, de fato, de constituir um coletivo de professores a partir de determinadas estruturas educacionais.

Depois disso, o terceiro passo na implementação de uma Clínica da Atividade Docente nas escolas é enfrentar o trabalho concreto de sala de aula com esse coletivo.

Dentre os vários métodos clínicos disponíveis e possíveis para essa implementação, destacaremos e detalharemos a seguir os dois mais frequentemente utilizados: o método da autoconfrontação simples e cruzada e o método da instrução ao sósia. Para exemplificar a utilização desses métodos, serão apresentadas duas ações realizadas, uma com professores universitários; e outra com professores da educação básica, tendo como observadores futuros professores, estudantes de licenciatura.

\section{O dispositivo metodológico de autoconfrontação e um relato de intervenção}

Esta seção apresenta o dispositivo metodológico de autoconfrontação em duas subseções. Na primeira, traz algumas questões teóricas de modo sucinto, porém, sem perder de vista a importância da engrenagem conceitual que move tal dispositivo e leva o sujeito autoconfrontado a tomar consciência de como agiu e de como poderá agir em sua atividade. Na segunda, proporciona ao leitor o acesso a um exemplo de realização de autoconfrontação.

\section{O que é a autoconfrontação?}

A autoconfrontação é um dispositivo metodológico de intervenção clínica, em que o trabalhador tem a oportunidade de ver imagens de si em ação e, a partir disso, dialogar com ele mesmo, com um interveniente e com um par da profissão, a fim de analisar sua atividade e 
perceber o que pode fazer de diferente nela (CLOT, 2010; ALTHAUS, 2019). O interveniente "é a pessoa que conduz as autoconfrontações [...] sua função nas intervenções é provocar o sujeito participante a se observar em ação e perceber qual(is) mudança(s) precisa(m) ser implementa(s) em sua atividade" (ALTHAUS, 2019, p. 15) ${ }^{5}$.

O dispositivo metodológico de autoconfrontação nasceu de uma experiência dialógica de análise de trabalho conduzida e estudada pelo linguista Daniel Faïta a partir do método de autoconfrontação simples empregado na ergonomia (FAїTA, 1989; 1997; 2007; 2017), mais tarde foi adaptado para a Clínica da Atividade (CLOT; FAïTA, 2000).

Tal como está organizado, o dispositivo segue alguns procedimentos, que, segundo Clot (2010), podem ser descritos em três fases com várias etapas cada.

A primeira fase antecede as autoconfrontações e é um momento de organização coletiva da demanda de intervenção clínica, de constituição de uma dupla de trabalhadores para participar diretamente das autoconfrontações, de observação de cada profissional em ação pelos intervenientes e de problematização com eles sobre o que foi observado (CLOT, 2010).

A segunda é o momento de realização das autoconfrontações. Nessa fase, os trabalhadores são filmados em ação e uma amostra das imagens é recortada para que cada profissional se visualize e análise sua atividade, por meio de um diálogo consigo mesmo, com o interveniente e com seu ofício. Na autoconfrontação simples cada trabalhador analisa sua própria ação na companhia do interveniente, já na autoconfrontação cruzada cada um analisa a atividade do seu par na presença dele e os dois dialogam sobre isso com a mediação do interveniente. Nessas etapas, busca-se a controvérsia de diferentes modos de agir e de pensar, bem como a identificação de diferentes possibilidades para se realizar a atividade (CLOT, 2010).

E, a terceira fase, trata do retorno ao coletivo, a fim de ampliar as análises e buscar juntos alguma(s) possibilidade(s) de solução para a demanda (CLOT, 2010).

Destaca-se que todos esses procedimentos envolvem um movimento psico-dialógico,

\footnotetext{
${ }^{5}$ O termo interveniente foi uma opção de tradução da tese de Althaus (2019) para o intervenant utilizado na Clínica da Atividade Francesa. Além disso, cabe ressaltar que essa tese apresentou e estudou uma metodologia de formação de intervenientes com pares mais experientes, tanto para realizar a autoconfrontação, quanto nos momentos que a antecedem, para se preparar, e nos momentos que a sucedem, para estudá-la. O leitor que desejar mais informações poderá acessar http://repositorio.unicamp.br/jspui/bitstream/REPOSIP/335042/1/Althaus_Dalvane_D.pdf. Acesso em: 11 jun. 2021.
} 
em que o sujeito, ao ser observado por outro ou ao ser filmado pela câmera, passa a observar a si mesmo e a perceber como realiza sua atividade e como poderá mudá-la (se for o caso). Esse processo de auto-observação se amplia quando o sujeito vê a si mesmo em imagens e é convidado a analisá-las, e, ainda mais, quando tem a oportunidade de se ver por meio da ação de um colega e dialogar com ele (CLOT, 2010; LIMA, 2016; ALTHAUS, 2019; 2020a).

Além disso, nesse movimento psico-dialógico se espera o desenvolvimento de alguns processos, tais como: o "difícil de dizer", quando o sujeito estranha a sua própria atividade; a tentativa de "refúgio no coletivo", em geral, desamparada pelo par de autoconfrontação e, com isso, a instalação de uma "controvérsia" sobre os modos de pensar e fazer; a construção de um "terceiro ponto de vista", mais amplo e com evidenciação do "real da atividade", aquilo que poderia ter sido feito e não foi, mas que poderá ser efetivado em uma ação futura, levando à "estilização" do "gênero de atividade" (CLOT, 2010; LIMA, 2016, ALTHAUS, 2019; 2020a).

\section{Relato da realização de uma autoconfrontação ${ }^{6}$}

Nesta subseção, trazem-se alguns dados para relatar uma intervenção com autoconfrontação. Trata-se de uma intervenção realizada por uma Clínica da Atividade Docente (CAD) (LIMA, 2016), na Universidade Tecnológica Federal do Paraná, Câmpus Pato Branco (UTFPR-PB).

Nesta instituição, os docentes estão organizados por Departamentos Acadêmicos de acordo com suas áreas de conhecimento, sendo eles: Administração, Agrimensura, Agronomia, Ciências Contábeis, Civil, Elétrica, Física, Humanidades, Informática, Letras, Matemática, Mecânica e Química. Em diversos momentos, os docentes manifestam a necessidade de tratar de questões pedagógicas referentes as suas práticas de sala de aula, tanto em momentos de formação docente continuada já realizadas (ALTHAUS, 2013), quanto nos contínuos momentos de diálogo dos professores(as) com a CAD.

Nesse âmbito, o líder da CAD, Prof. Dr. Anselmo Pereira de Lima, com a colaboração da

\footnotetext{
${ }^{6}$ Aqui será apresentado um breve relato de uma intervenção com autoconfrontação. 0 leitor que desejar mais informações poderá consultar Althaus (2013) para acessar uma análise detalhada da intervenção, no link <http://repositorio.utfpr.edu.br/jspui/bitstream/1/755/1/PB_PPGDR_M_Althaus\%2c\%20Dalvane_2013.pdf> Acesso em: 11 jun. 2021.
}

Periódico Horizontes - USF - Itatiba, SP - Brasil - e021036 
Pedagoga Dra Dalvane Althaus, propôs, em 2010, junto aos coletivos de professores, por meio de reuniões pedagógicas realizadas com os Coordenadores de Curso e com os docentes por Departamentos, a realização de autoconfrontação com duplas de docentes voluntários de cada

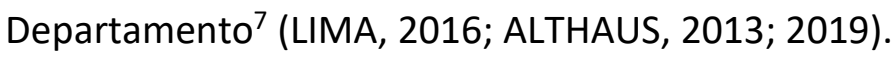

Com as duplas de professores(as) voluntários(as) constituídas, passou-se para a efetivação das intervenções, sendo que até o momento foram atendidas cinco duplas das

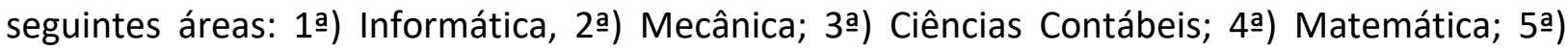
Química. Para este texto, traz-se uma amostra da autoconfrontação com a primeira dupla de professores de Informática.

A dupla de docentes da informática foi identificada nos dados como Professor A (PA) e Professor (PB). Os dois indicaram, para realizar a filmagem, a mesma turma de alunos do terceiro período do curso em Tecnologia em Análise e Desenvolvimento de Sistemas e com atividades desenvolvidas no mesmo laboratório, sendo que PA ministrava a disciplina Programação Orientada a Objetos e o PB a de Instalação e Configuração de Serviços de Rede.

Os intervenientes ${ }^{8}$ visitaram as turmas, com cada professor separadamente, para coletar as autorizações livres e esclarecidas dos alunos e os colocar a par dos procedimentos.

Na semana seguinte, assistiram a uma aula de cada professor e tomaram notas, o mais descritivas possível, que depois foram tematizadas com os docentes, e isso possibilitou a identificação de situações de indisciplina mal resolvidas em sala aula desse curso. Isso porque as aulas de informática são em laboratórios em que cada aluno dispõe de um computador para efetuar os comandos emitidos pelos professores, porém, os docentes perceberam que frequentemente os estudantes entravam em sites diferentes daqueles trabalhados em sala de aula e acabavam se dispersando dos estudos.

$\mathrm{Na}$ semana consecutiva, filmaram uma aula de cada professor e selecionaram um trecho de aproximadamente cinco minutos para serem temas das autoconfrontações.

No trecho de aula empregado na autoconfrontação com o PA, e registrado em videodocumentário (LIMA; ALTHAUS, 2011a), o Professor se encontra trabalhando com os

\footnotetext{
${ }^{7}$ Obtivemos mais de duas duplas de docentes voluntários em cada Departamento.

${ }^{8} \mathrm{Na} C A D$, as intervenções são realizadas por duplas de intervenientes. Em geral, o mais experiente tem a função de ser o principal condutor da ação e formador de outro interveniente que, por sua vez, participa como auxiliar, tendo o papel de observar e intervir quando se sente apto (ALTHAUS, 2019).
} 
alunos em um Laboratório de Informática, em pé e inclinado, digitando comandos em seu notebook, que também são projetados em tela para que os alunos os acompanhem e executem em seus computadores. Os estudantes, por sua vez, se encontram cada um sentado junto a bancadas com computadores a sua frente para efetuarem suas tarefas de aula. Ao explicar o conteúdo, o PA aponta na tela o que deseja chamar atenção dos alunos.

No trecho de aula empregado na autoconfrontação com PB, e registrado em videodocumentário (LIMA; ALTHAUS, 2011b), o PB se encontra trabalhando com os mesmos alunos e no mesmo Laboratório de Informática, sentado junto a sua mesa, digitando em seu notebook comandos que são simultaneamente projetados na tela e acompanhados pelos alunos, que devem também executá-los em suas máquinas. De uma série de informações que foram projetadas na tela, o PB seleciona um trecho e explica o conteúdo aos alunos do lugar onde se encontrava: sentado junto à mesa, atrás de seu notebook.

Na autoconfrontação simples com o PA, este, ao analisar suas imagens, relatou que há um problema com todos os laboratórios de Informática: a mesa em que fica o notebook do Professor é baixa. E que se inclina ao digitar para compensar a falta de uma mesa mais alta, em que poderia inserir os dados no computador e, ao mesmo tempo, manter o contato visual com os alunos e a mobilidade para chamar atenção ao que considera mais importante, apontando na tela (ALTHAUS, 2013).

$\mathrm{Na}$ autoconfrontação simples com o PB, ele destacou de modo autocrítico que selecionou um longo trecho de informações de onde se encontrava sentado atrás de seu notebook. Mas, o PB justifica que levantar e sentar é desgastante, atrapalha o segmento da aula e demanda um tempo de aula que pode ser economizado se ficar somente sentado seguindo uma determinada cronologia de aula, entretanto, considera que para a aprendizagem dos alunos seria mais interessante levantar e apontar na tela, indo parte por parte. O professor percebeu que ao perder o contato visual com os alunos eles se distanciam da aula e passam a navegar por sites estranhos à atividade de ensino-aprendizagem, isto é, apresentam um comportamento indisciplinado (ALTHAUS, 2013).

$\mathrm{Na}$ autoconfrontação cruzada com a aula do PA, os professores entram em controvérsia diante de uma diferença de pontos de vista: para o PB, sentado há um ganho para o Professor e uma perda para o aluno e vice e versa; para o PA a perda do aluno é perda para o Professor, 
também, e vice e versa.

$\mathrm{Na}$ autoconfrontação cruzada com a aula do PB, a controvérsia se configurou em torno do gesto de digitar inclinado, pois para o PA é uma forma de continuar em contato com os alunos e para o PB digitar inclinado prejudica a saúde física. Contudo, PB percebeu que seu colega em pé conseguia levar os alunos a ter um foco de atenção e ele não, sendo que isto lhe causa mal-estar (ALTHAUS, 2013).

A partir dos diálogos travados nas autoconfrontações, os intervenientes editaram um videodocumentário ${ }^{9}$ sobre a aula de cada professor, com a validação deles, e os levaram para discutir a temática com o coletivo do Departamento de Informática, onde PA e PB estão lotados, e com os demais docentes do Câmpus. Assim, os outros professores tiveram a oportunidade de pensar em suas aulas e em suas dificuldades, que revelaram ser semelhantes.

Outro desdobramento foram algumas tentativas de produzir uma mesa com altura regulável, mobilidade e segurança. Inicialmente, pensou-se em adquirir uma mesa que atendesse a necessidade dos professores. Contudo, as mesas com regulagem de altura disponíveis no mercado não eram condizentes com a finalidade de uso para sala de aula. $E$, ao compartilhar o videodocumentário com o coletivo da Mecânica, um professor se sensibilizou com a situação e se propôs, junto com seus orientandos, a produzir um protótipo (ALTHAUS, 2013).

Além disso, os membros da CAD debruçam-se sobre os dados para estudá-los. Em Althaus (2013), fez-se uma análise de todos os dados produzidos com essa dupla de docentes. Destacou-se o desenvolvimento profissional docente de PB, por meio de tomadas de consciência ${ }^{10}$ manifestadas em seu discurso, a exemplo do enunciado "eu poderia ter" que foi repetido por ele diversas vezes e indicam possibilidades não realizadas, real da atividade, que poderão no futuro serem implementadas. Constatou-se que o gesto de digitar inclinado pode trazer consequências para a saúde física do professor e que a indisciplina dos alunos, ligadas ao distanciamento do professor que se senta, pode trazer prejuízos para a saúde mental do

${ }^{9} \mathrm{O}$ vídeodocumentário é composto por trechos de aula, de autoconfrontação simples e de autoconfrontação cruzada.

${ }^{10}$ A "tomada de consciência" é um conceito importante para a Clínica da Atividade, uma vez que trata-se da "redescoberta da atividade em outra possibilidade de realização [...] uma espécie de vivência psicológica a partir de outras experiências vividas [...] é uma atividade transformadora da experiência subjetiva, é uma metamorfose do passado, com potencial para a estilização" (ALTHAUS, 2019, p.44). 
docente. No estudo em questão, concluiu-se que digitar em pé é um gesto profissional docente complexo e relevante, de modo que:

a complexidade do gesto profissional docente de trabalhar em pé está na recriação estilística que ele proporciona. A relevância desse mesmo gesto está na função que ele exerce no processo de ensinoaprendizagem em que o professor consegue engajar os alunos para um foco de estudo (ALTHAUS, 2013, p. 124). ${ }^{11}$

Em outro texto de Lima e Althaus (2016) sobre os mesmos dados, demonstrou-se a necessidade de estabelecer relações entre a formação docente continuada, o desenvolvimento de práticas pedagógicas em sala de aula e a promoção da saúde do professor, a partir de uma análise específica dos gestos docentes de trabalhar sentado, inclinado e em pé. Com isso, apontaram-se aspectos de insustentabilidade e sustentabilidade na oscilação entre os gestos de sentar para digitar e levantar para ministrar a aula, bem como o de inclinar para tentar fazer as duas atividades ao mesmo tempo e, ainda, compensar a falta de uma mesa na altura adequada.

$\mathrm{Na}$ continuidade das intervenções e estudos se tem reafirmado a importância do dispositivo de autoconfrontação que se distingue de uma mera metodologia de formação docente continuada tradicional, em que especialistas externos dizem aos professores o que eles devem fazer, mas como uma possibilidade de desenvolvimento de práticas docentes "tendo a atividade em movimento como centro de análise e os trabalhadores como protagonistas" (ALTHAUS, 2019, p.34). Em outras palavras:

[...] ter a atividade de ensinoaprendizagem como centro de análise possibilita perceber novas formas de viver na docência através da experiência de trabalho vivida, e ter o professor como protagonista é respeitar a subjetividade e creditar sua capacidade de especialista no que faz (ALTHAUS, 2020b, p.81).

Assim sendo, cabe salientar que "o papel do interveniente é servir de suporte para

${ }^{11}$ Como já mencionado, ressalta-se que o leitor que desejar conhecer mais detalhes deste estudo, tal como o desenvolvimento de questões sobre o real da atividade e recriações estilísticas, poderá o consultar na integra em Althaus (2013).

Periódico Horizontes - USF - Itatiba, SP - Brasil - e021036 
instigar o sujeito que participa da autoconfrontação a entrar no processo de observar-se, de analisar e interpretar suas próprias ações e de identificar o real da atividade" (ALTHAUS, 2019, p. 126), provocando o diálogo do sujeito consigo mesmo e com outros, bem como explorando o "difícil de dizer" e as "controvérsias" (CLOT, 2010).

\section{O método instrução ao sósia e um relato de intervenção}

Nesta seção, primeiramente, será abordado o método instrução ao sósia, que, assim como a autoconfrontação, visa criar uma situação que propicia o desenvolvimento humano, tendo como referências teóricas de base, em especial, Clot (2006, 2010), entre outros. Em segundo lugar, será apresentado um relato de uma intervenção realizada com esse método em uma universidade, tendo como objetivo não a transformação da situação de trabalho pelos profissionais, mas uma possibilidade de formação com alunos de licenciatura, futuros professores.

O método instrução ao sósia é um legado do médico e psicólogo Ivar Oddone, na cidade de Turim, Itália, nos anos de 1970, período em que as relações de trabalho estavam em grandes mudanças, situação deixada pela Revolução Industrial e a produção em massa. Nesse período, nas indústrias, eram comuns problemas de saúde do trabalhador, fato que passou a chamar a atenção de estudiosos, sindicalistas e profissionais da saúde. Oddone, líder técnicocientífico do Movimento Operário Italiano (MOI), inicia seus trabalhos de pesquisa com o objetivo de identificar as causas do sofrimento em ambientes de trabalho, sendo necessário, desse modo, desenvolver métodos de intervenção voltados à obtenção de dados, sem perder de vista o desenvolvimento do trabalhador (ANJOS, PAGNONCELLI, MUNIZ-OLIVEIRA, 2020). Esse movimento, $\mathrm{MOI}$, engajado na luta pela saúde dos trabalhadores, valorizavam a experiência, o saber dos trabalhadores. Inicialmente, pesquisadores do MOI faziam entrevistas com o trabalhador para registros sobre o seu trabalho.

Nessa luta em busca de melhores condições de saúde ao trabalhador, um novo método é concebido pelos pesquisadores, a instrução ao sósia, que se tratava de uma situação de diálogo, um tipo de conversa entre o trabalhador e um membro da equipe do MOI.

Para dar início à conversa, havia uma orientação que era dada por Oddone ou por um 
membro de sua equipe:

Se existisse outra pessoa perfeitamente idêntica a você do ponto de vista físico, como você o instruiria para se comportar na fábrica com relação às tarefas, aos seus colegas de trabalho, à hierarquia e à organização sindical (ou outras formas organizativas) de forma que ninguém perceba que se trata de outro e não de você? (ODDONE; RE; BRIANTE, 1981, p.57, apud MUNIZ, 2013, p. 288).

Neste método, o trabalhador-sósia tendo em mente uma situação fictícia, em que deveria substituir o trabalhador-instrutor, precisa compreender os planos e estratégias utilizados na atividade de trabalho, assim, solicita que as instruções sejam detalhadas, levando o trabalhador-instrutor a fornecer-lhe os detalhes, as minúcias para realizar o seu trabalho. Os dados produzidos tratam-se da imagem, da representação que o trabalhador faz de seu próprio comportamento (ODDONE; RE; BRIANTE, 1981, apud MUNIZ, 2013).

O psicólogo francês Yves Clot do CNAM de Paris, França, faz uma releitura deste método que, segundo ele, visa a uma transformação indireta dos trabalhadores, já que as atividades de trabalho, ao se transformarem em linguagem, reorganizam-se e modificam-se (CLOT, 2010). Além da Psicologia, as pesquisas de Clot partem de estudos da área da linguagem aliados às ciências do trabalho, tendo como maiores expoentes Liev Semiónovitch Vigotski (2001), no que tange ao desenvolvimento humano alicerçado na relação entre atividade e fala; e em pressupostos bakhtinianos, em que o discurso está diretamente relacionado à atividade humana.

O desenvolvimento estaria associado à fala social, egocêntrica e interior, sendo que a fala egocêntrica vai, aos poucos, tornando-se apropriada para o planejamento e resolução de problemas, à medida que as atividades da criança [nesse caso, de adultos trabalhadores] tornam-se mais complexas (VIGOTSKI, 2001). A instrução ao sósia, assim como a autoconfrontação, tem como principal função desenvolver a função psicológica do coletivo para levar a novas possibilidades de pensar e de agir (CLOT, 2017).

No contexto do CNAM, em uma primeira etapa, a sessão de instrução ao sósia é gravada, para que em seguida seja feita a sua transcrição. Numa segunda etapa, o trabalhadorinstrutor se autoconfronta com o texto transcrito, tecendo comentários por escrito, com suas 
reflexões, sobre as instruções dadas. Esse texto com reflexões é destinado a discussões com o coletivo de trabalhadores (CLOT, 2006, 2010). Ainda, nesse mesmo contexto, o método também tem sido utilizado em situações de formação contínua e de formação inicial, conforme mencionado em Muniz-Oliveira (2015). A seguir, há o relato de uma experiência com a utilização apenas da primeira etapa no contexto de formação inicial.

\section{Relato de uma intervenção com o método instrução ao sósia}

Nesta seção, será apresentada uma ação de formação docente aplicada em uma disciplina em um curso de licenciatura da UTFPR, Campus Dois Vizinhos, com a realização de uma sessão de instrução ao sósia, tendo, portanto, um caráter interventivo.

A sessão de instrução ao sósia teve como objetivo contribuir com a formação dos alunos, estudantes da disciplina, no que se refere a aspectos relacionados à área da docência, já que estavam no processo de formação para se tornarem habilitados a serem professores e atuarem na profissão. Segundo Lousada (2017, p.98), “A formação pode ser realizada de inúmeras maneiras. Por exemplo, partindo de textos que abordam questões didáticas [...]". Neste caso, um momento de formação a ser aqui relatado se deu a partir da participação dos alunos como observadores em uma sessão de instrução ao sósia, em que puderam, após o término da sessão, participar com perguntas, observações, comentários sobre a experiência vivida de um professor em sala de aula. Segue a contextualização da atividade realizada.

Esta atividade interventiva foi realizada em uma disciplina optativa denominada Redação Científica do curso de Licenciatura em Ciências Biológicas entre 2018 e 2019. Os alunos dessa disciplina já tinham cursado a metade ou a maioria das disciplinas, tendo alguma experiência em escolas, pois muitos já tinham cursado ou estavam cursando a disciplina de estágio supervisionado, com atuação nas etapas de observação e de regência em sala de aula. Além disso, muitos deles eram ou tinham sido bolsistas do Programa Institucional de Bolsas de 
Iniciação à Docência (PIBID) ou do Programa Residência Pedagógica ${ }^{12}$, tendo participado em projetos educativos em escolas estaduais do município, com vivência em salas de aulas do ensino fundamental e médio.

No caso da disciplina em que a atividade foi realizada, de acordo com sua ementa, seu objetivo é fornecer noções básicas de redação científica. Assim, foi proposta como avaliação final para esta disciplina a produção de um artigo científico, um desafio para além de noções básicas de redação científica. Para isso, nas primeiras semanas da disciplina, foi trabalhado um texto sobre instrução ao sósia (MUNIZ-OLIVEIRA, 2009) para que os alunos tivessem alguma noção sobre esse método, pois a proposta era convidar professores da educação básica do município para que participassem em uma sessão de instrução ao sósia em uma aula da disciplina, com a presença dos alunos da turma. Especificamente, o objetivo desta ação era contribuir com a formação dos licenciandos, já que um professor experiente, protagonista de seu trabalho, iria abordar o seu trabalho em sala de aula ao dar as instruções. Simultaneamente, visava possibilitar o desenvolvimento de capacidades de linguagem referentes à redação científica, pois a proposta era a de que o texto oral produzido em situação de instrução ao sósia fosse utilizado como corpus de análise para a produção de um artigo científico, trabalho final proposto para a disciplina.

Tendo a concordância dos alunos, que demonstraram empolgação, foi solicitado a eles que indicassem professores da área de Ciências Biológicas do ensino fundamental (60 ao 9o ano) ou do ensino médio para participarem em uma sessão de instrução ao sósia, pois, como eles já tinham atuação nas escolas, como já mencionado, conheciam vários docentes da rede estadual. Foi mencionada a importância de serem professores experientes, por ser considerado um fator que poderia contribuir com a formação desses estudantes do curso de licenciatura. Assim, em cada semestre letivo (01/2018,02/2018,01/2019), pois a disciplina era semestral, os alunos indicaram professores que tinham experiência na docência, considerados profissionais mais apropriados para participarem da sessão de instrução ao sósia. Os alunos estabeleceram um primeiro contato e convite ao professor, sendo este formalizado pela professora da

\footnotetext{
12 Programas que fazem parte da Política Nacional de Formação de Professores, que incentivam a vivência da prática dos formandos dentro da aula, ofertando auxílio em bolsas para esses alunos. Disponível em: https://www.capes.gov.br/36noticias/10203-capes-reabre-prazos-para-pibid-e-residencia-pedagogica. Acesso em: 24 set. 2020.
} 
disciplina, ocasião em que foi dada uma breve explicação sobre o método e sobre o objetivo da atividade, deixando bem claro que o propósito não era, de forma alguma, avaliar o trabalho do professor, e sim conhecer um pouco o dia a dia da sala de aula, de acordo com sua experiência que seria verbalizada.

Desse modo, os alunos de cada turma dos três semestres mencionados participaram de uma sessão de instrução ao sósia, conforme segue a descrição e exposição abaixo.

\section{Descrição e resultados da ação realizada}

Nos três semestres letivos mencionados, o contexto de realização das sessões de instrução ao sósia foi semelhante. As aulas da disciplina ocorreram às sextas-feiras, das $19 \mathrm{~h}$ às 21h15min, e o local de realização da sessão de instrução ao sósia foi a própria sala de aula na universidade. Assim, nesses três semestres, três professoras experientes foram convidadas a serem as voluntárias. Na aula anterior à sessão de instrução ao sósia, foram dadas orientações aos alunos para eles fazerem a gravação em áudio no momento da sessão de instrução ao sósia para que o texto oral pudesse ser transcrito posteriormente.

No início das aulas em que foram realizadas as sessões de instrução ao sósia, foi solicitado aos alunos que eles fizessem anotações sobre dúvidas ou questionamentos sobre a fala da professora voluntária. Após a professora chegar à sala, antes de iniciar a sessão, de modo breve, foram dadas orientações às professoras sobre o funcionamento do método, por exemplo, que elas deveriam dar instruções a uma "sósia" (professora da UTFPR, substituta hipotética), com detalhes, sobre como realizar o seu trabalho na sala de aula, sendo necessária a utilização pela professora-instrutora do pronome "você" ao dar as instruções à sósia. Além disso, antes de dar início, seguindo as normas para realização de uma pesquisa ${ }^{13}$, as professoras voluntárias assinaram o termo de consentimento livre e esclarecido. Após essas etapas, passou-se à abertura da sessão de instrução ao sósia, tendo como base a orientação inicial que faz parte do método, conforme mencionado; foi delimitada como atividade a ser objeto da instrução ao sósia as aulas seguintes que as professoras iriam ministrar, no caso, seriam as aulas da segunda-feira da semana subsequente.

${ }^{13}$ Trabalho vinculado ao projeto de pesquisa de Muniz-Oliveira (2016), aprovado no Comitê de Ética em Pesquisa. 
Durante a sessão, a professora da UTFPR colocou-se na posição de sósia que deveria substituir a professora-instrutora, conduzindo o diálogo de modo que pudesse compreender os mínimos detalhes das instruções. Assim, quando não compreendia determinada instrução, a sósia interrompia a instrutora para pedir um maior detalhamento de como deveria proceder em determinada situação. A sósia desempenhou o papel de interveniente (ver seção de autoconfrontação) na instrução ao sósia, ou seja, foi a pessoa que a conduziu; a forma de condução do diálogo é decisiva para obter uma maior riqueza em relação aos aspectos do trabalho e para proporcionar o desenvolvimento do instrutor-trabalhador ${ }^{14}$. Importante destacar que a professora interveniente era experiente em condução de sessão de instrução ao sósia, tendo utilizado esse método em sua tese de doutorado (MUNIZ-OLIVEIRA, 2015) e realizado outros trabalhos com este método.

No decorrer da sessão, ao dar as instruções, diversas temáticas foram abordadas, referentes a dificuldades vivenciadas na sala de aula e soluções encontradas no decorrer da profissão. Entre várias outras ${ }^{15}$, uma das temáticas que teve destaque foi relacionada ao perfil dos alunos e como lidar nas variadas situações. Por exemplo, a indisciplina em sala de aula, a falta de interesse dos alunos, diferenças de perfis dos alunos para apropriarem-se dos conhecimentos, diferenças entre turmas do mesmo ano, o uso da tecnologia pelos alunos em sala de aula, alunos com ausência de pré-requisitos, alunos com transtorno de neurodesenvolvimento, alunos com gravíssimos problemas na esfera familiar e, até mesmo, o uso de drogas em sala de aula.

Durante a sessão, os alunos ficaram atentos ao diálogo e faziam anotações sobre possíveis dúvidas ou perguntas, incluindo notas sobre a linguagem corporal e tom de voz das professoras, pois, ao dar instruções, em alguns momentos, elas mostravam-se afetadas de forma que deixavam transparecer na linguagem corporal ou no tom de voz, o que era percebido pelos alunos. Ao término, os alunos fizeram perguntas às professoras e teceram

\footnotetext{
${ }^{14}$ É evidente que são necessárias ações de uma Clínica de Atividade docente para professores em serviço.

${ }^{15}$ Outras temáticas e discussões abordadas na instrução ao sósia podem ser vistas no livro organizado por MunizOliveira, "O trabalho do professor da rede estadual revelado na linguagem na instrução ao sósia" (2020), pois o trabalho realizado na disciplina possibilitou um segundo momento de formação, em que os alunos fizeram a transcrição do texto oral da instrução ao sósia, realizaram análises do texto transcrito, o que os levou a reflexões sobre aspectos do trabalho docente. Esse trabalho, em um primeiro momento, levou à produção dos artigos científicos como trabalho final da disciplina; e, em segundo lugar, levou à organização deste livro mencionado.
} 
comentários, mostrando o quão positivo foi a participação na sessão de instrução ao sósia, deixando claro que este tipo de atividade de intervenção proporciona o conhecimento de aspectos do trabalho em sala de aula, desvelados na fala pelo próprio professor, protagonista do seu trabalho, o que não é trazido, geralmente, nas falas dos professores das disciplinas do curso, conforme revelado pelos próprios alunos.

A sessão de instrução ao sósia possibilitou a criação de uma relação dialógica entre licenciandos (professores em formação), professoras experientes (instrutoras) e professora interveniente (sósia), o que possibilitou reflexões sobre dificuldades que podem ser encontradas na futura profissão dos alunos, assim como formas de lidar com os problemas, buscando estabelecer uma zona potencial de desenvolvimento (MORAES, MAGALHÃES, 2017) para os alunos, futuros professores da área de Ciências Biológicas.

\section{Considerações finais}

Conforme apresentado, no âmbito escolar, a implementação de uma Clínica de Atividade Docente como forma de promoção da saúde física e mental do professor é necessária, sendo uma maneira de valorizar a experiência do próprio professor que atua na sala de aula e, portanto, conhece efetivamente o seu trabalho. Para que isso se torne possível, é necessário o apoio e comprometimento dos gestores e atores envolvidos neste processo.

Da mesma forma, no âmbito universitário, o pedagogo, com o apoio de seus superiores hierárquicos e pares, pode realizar ações para implementação de uma Clínica de Atividade, conforme visto na segunda seção. Para tanto, esse profissional também precisa passar por um processo de formação para se tornar interveniente e ter condições de mobilizar a abordagem teórico-metodológica da Clínica da Atividade em suas ações de mediação do desenvolvimento de práticas docentes.

Ainda, no âmbito universitário, o professor, em sua sala de aula, também pode promover ações de intervenção utilizando o arcabouço teórico e metodológico da Clínica da Atividade como forma de contribuir com a formação inicial de futuros professores. Para isso, é necessária, além de professores experientes voluntários do ensino fundamental e médio, a colaboração dos alunos, para os quais deve haver clareza nos objetivos da intervenção a ser realizada e um planejamento anterior muito bem delineado. 


\section{Referências}

ALTHAUS, D. Complexidade e relevância de um gesto profissional docente aparentemente simples. 2013. 200f. Dissertação (Mestrado em Desenvolvimento Regional) - Programa de PósGraduação em Desenvolvimento Regional, Universidade Tecnológica Federal do Paraná. Pato Branco, 2013. Disponível em:

http://repositorio.utfpr.edu.br/jspui/bitstream/1/755/1/PB_PPGDR_M_Althaus\%2c\%20Dalvan e_2013.pdf. Acesso em: 27 ago. 2020.

ALTHAUS, D. Aspectos da formação e do papel do interveniente na clínica da atividade: um estudo de caso em situação de autoconfrontação. 163f. 2019. Tese (Doutorado em Educação) Universidade Estadual de Campinas, Faculdade de Educação, Campinas, SP, 2019. Disponível em: http://repositorio.unicamp.br/jspui/bitstream/REPOSIP/335042/1/Althaus_Dalvane_D.pdf Acesso em: 31 jan. 2020.

ALTHAUS, D. Estudo sobre aspectos da formação e do papel do interveniente na clínica da atividade: em situação de autoconfrontação. In: SILVESTRE, L. P. F. (org.) Ciências sociais aplicadas: avanços, recuos e contradições. Ponta Grossa: Atena, 2020a, p.204-221.

ALTHAUS, D. Embates e perspectivas do trabalho pedagógico com desenvolvimento de práticas docentes. Trabalho \& Educação. v.29, n.1, p.75-93, jan-abr 2020b. Disponível em: https://periodicos.ufmg.br/index.php/trabedu/article/view/20219/17619. Acesso em: 27 ago. 2020.

ANJOS, D. D.; PAGNONCELLI, C.; MUNIZ-OLIVEIRA, S. Clínica da atividade e o método instrução ao sósia. In: MUNIZ-OLIVEIRA, S. (org.). O trabalho do professor da rede estadual revelado na linguagem na instrução ao sósia. Campinas: Pontes, 2020, p.19-33.

BERMÚDEZ, A. C. Pisa: Brasil fica entre piores, mas à frente da Argentina; veja ranking. UOL, São Paulo, 03 de dezembro de 2019. Disponível em:

https://educacao.uol.com.br/noticias/2019/12/03/pisa-brasil-fica-entre-piores-mas-a-frenteda-argentina-veja-ranking.htm. Acesso em: 22/03/2021.

CLOT, Y. A função psicológica do trabalho. Petrópolis: Vozes, 2006.

CLOT, Y. Trabalho e poder de agir. Trad. Guilherme João de F. Teixeira e Marlene M. Z. Vianna. Belo Horizonte: Fabrefactum, 2010.

CLOT, Y. L'institution compte sur les enseignants mais ne fait rien pour eux. [Entrevista cedida a] I'Humanité. Quarta-feira, 3 de fevereiro de 2016. Disponível em:

https://www.humanite.fr/yves-clot-linstitution-compte-sur-les-enseignants-mais-ne-fait-rienpour-eux-597998. Acesso em: 22 mar. 2021.

CLOT, Y. Clínica da atividade. Horizontes, Itatiba. v.35, n.3, p.18-22, 2017. Disponível em: 
https://revistahorizontes.usf.edu.br/horizontes/issue/view/24/showToc. Acesso em: 09 jul. 2020.

CLOT, Y.; FAÏTA, D. Genre et style en analyse du travail, concepts et méthodes. Travailler, Paris, n.4, p.7-42, 2000.

FAïTA, D. Mondes du travail et pratiques langagières. Langages, n.93, p.110-123, 1989.

FAÏTA, D. La conduite du TGV: exercices de styles. Champs Visuels, Paris, n.6, p.123-129, 1997.

FAïTA, D. L'image animée comme artefact dans le cadre méthodologique d'une analyse clinique de l'activité. Activités, v.4, n.2, p.3-15, 2007.

FAïTA, D. Entrevista: De l'enseignement de la linguistique générale à l'analyse du travail enseignant. [Entrevista cedida a] Daniela Anjos e Ermelinda Barricelli. Horizontes, v.35, n.3, p. 8-17, 2017.

FERREIRA, A. B. H. Miniaurélio Século XXI Escolar: o minidicionário da língua portuguesa. 4. ed. rev. Ampliada. Rio de Janeiro: Nova Fronteira, 2000.

LIMA, A. P. Blog. Clínica da Atividade Docente. 2016. Disponível em:

https://formacaoesaudedoprofessor.com/sobre-o-blog/. Acesso em: 17 ago. 2020.

LIMA, A. P. Como transformar a prática docente nas escolas: guia definitivo para o coordenador pedagógico. Campinas, SP: Pontes Editores, 2021.

LIMA, A. P.; ALTHAUS, D. Formação docente continuada. UTFPR - Campus Pato Branco: Vídeo II, 2011a. Disponível em: http://www.youtube.com/watch?v=umyPiho_2xE. Acesso em: 27 ago. 2020.

LIMA, A. P.; ALTHAUS, D. Formação docente continuada. UTFPR - Campus Pato Branco: Vídeo I, 2011b. Disponível em: http://www.youtube.com/watch?v=J1B2KnVUDCY. Acesso em: 27 ago. 2020.

LIMA, A. P.; ALTHAUS, D. Formação docente continuada, desenvolvimento de práticas pedagógicas em sala de aula e promoção da saúde do professor: relações necessárias. Revista Brasileira de Estudos Pedagógicos. v.97, n.245, jan./abr. 2016.

LOUSADA, E. Intervenção, pesquisa e formação: aprendizagem do trabalho educacional e desenvolvimento de professores. Horizontes, v.35, n.3, p.94-104, set./dez. 2017.

MORAES, R. A. A.; MAGALHÃES, E. M. Abordagem clínica na análise da atividade docente: uma via unindo pesquisa, intervenção e formação. Horizontes, v.35, n.3, p.105-120, set./dez. 2017.

MUNIZ, H. P. et al. Ivar Oddone e suas contribuições para o campo da saúde do trabalhador no Brasil. Revista Brasileira de Saúde Ocupacional, São Paulo, v.38, n.128, p.280-291, 2013. 
Disponível em: https://www.scielo.br/pdf/rbso/v38n128/15.pdf. Acesso em: 13 out. 2020.

MUNIZ-OLIVEIRA, S. A instrução ao sósia e a formação docente. In: CONGRESSO DE LEITURA DO BRASIL, 17., 2009, Campinas. Anais [...]. Campinas: Unicamp, 2009, s./p. Disponível em:

http://alb.com.br/arquivo-

morto/edicoes_anteriores/anais17/txtcompletos/sem20/COLE_1046.pdf.

Acesso em: 17 jun. 2020.

MUNIZ-OLIVEIRA, S. O trabalho docente no ensino superior: múltiplos saberes, múltiplos fazeres do professor de pós-graduação. Campinas: Mercado de Letras, 2015.

VIGOTSKI, L. S. A construção do pensamento e linguagem. Trad. Paulo Bezerra. São Paulo: Martins Fontes, 2001.

Recebido em outubro 2020.

Aprovado em fevereiro 2021. 